\title{
TEM Characterization of Ag Precipitates in Screen Printed Ag Contacts for Si Solar Cells
}

\author{
K.M. Jones ${ }^{*}$, Y.Yan $^{*}$, M.M. Al-Jassim ${ }^{*}$ and M.M. Hilali** \\ *National Renewable Energy Laboratory, Golden, CO 80401, USA \\ ** Georgia Institute of Technology, Atlanta, GA 30332, USA
}

Over the years numerous processing schemes for metal-to-semiconductor contacts have been devised to produce quality ohmic contacts on low sheet-resistance emitters for $\mathrm{Si}$ solar cells. However, new techniques are required to produce the same results on high sheet-resistance (80-100 $\Omega / \mathrm{sg}$ ) emitters. Screen-printed Ag paste for contacts is a method used in the fabrication of these contacts. The Ag paste is comprised of several components including a glass frit that can react with the $\mathrm{Si}$ and have various effects on the quality of the contact. We have performed an in-depth structural and chemical study of the Ag-Si contact interfacial region in these devices using a FEI TF20 Ultra-Twin STEM and a variety of other analytical techniques. In this paper, we have focused on the structure, size distribution, and the penetration depth of Ag precipitates or crystallites at the AgSi contact interface region.

Firing or curing temperatures in the range of $750^{\circ} \mathrm{C}$ to $850^{\circ} \mathrm{C}$ are used to form the contact. During this process Ag precipitates or crystallites form at the interface. The size, density and depth of these precipitates are critical in producing a high quality ohmic contact that doesn't shunt the p-n junction. We found that a large number of the Ag precipitates inside Si exhibit the pyramidal shape. Figure 1 shows a high-angle annular dark-field scanning TEM (ADF-STEM) of a cross-sectional sample fired at $850^{\circ} \mathrm{C}$. X-ray energy dispersive spectroscopy (EDS) revealed that the bright pyramid shaped precipitates are rich in Ag. The sizes of the Ag precipitates are found to be very non-uniform. In some areas, the Ag precipitates can be as small as a few nano-meters, but at other areas, they can be as big as a few hundred nano-meters. Their distributions are also non-uniform. These $\mathrm{Ag}$ precipitates can even penetrate into the $\mathrm{Si}$ at a depth of about $100 \mathrm{~nm}$, which is in the p-n junction and can cause shunting of the device. Thus, these large precipitates are harmful to the device performance.

All of the pyramidal shaped Ag precipitates are found to have the same orientation. They have a close crystallographic relationship with the Si substrate. The relationship was determined by highresolution lattice imaging. Figure 2 shows a HR-TEM lattice image of a Ag precipitate. It revels that the growth front of the pyramids is on the $\mathrm{Si}\{111\}$ surfaces.

\section{References}

[1] M.M. Hailali, A.Rohatgi, C. Khadilkar, S. Kim, T. Pham, J. Salami, A Shaikh and S. Sridaran, Proc.of $19^{\text {th }}$ European Photovoltaic Solar Energy Conference, Paris, France June 2004. [2] C. Ballif, D.M. Huljic, A. Hessler-Wysser, and G Willeke, Proc. Of the $29^{\text {th }}$ IEEE PVSC, New Orleans, 2002,pp.360-363.

[3] This work was performed under DOE Contract \#DE-AC36-99GO10337. 

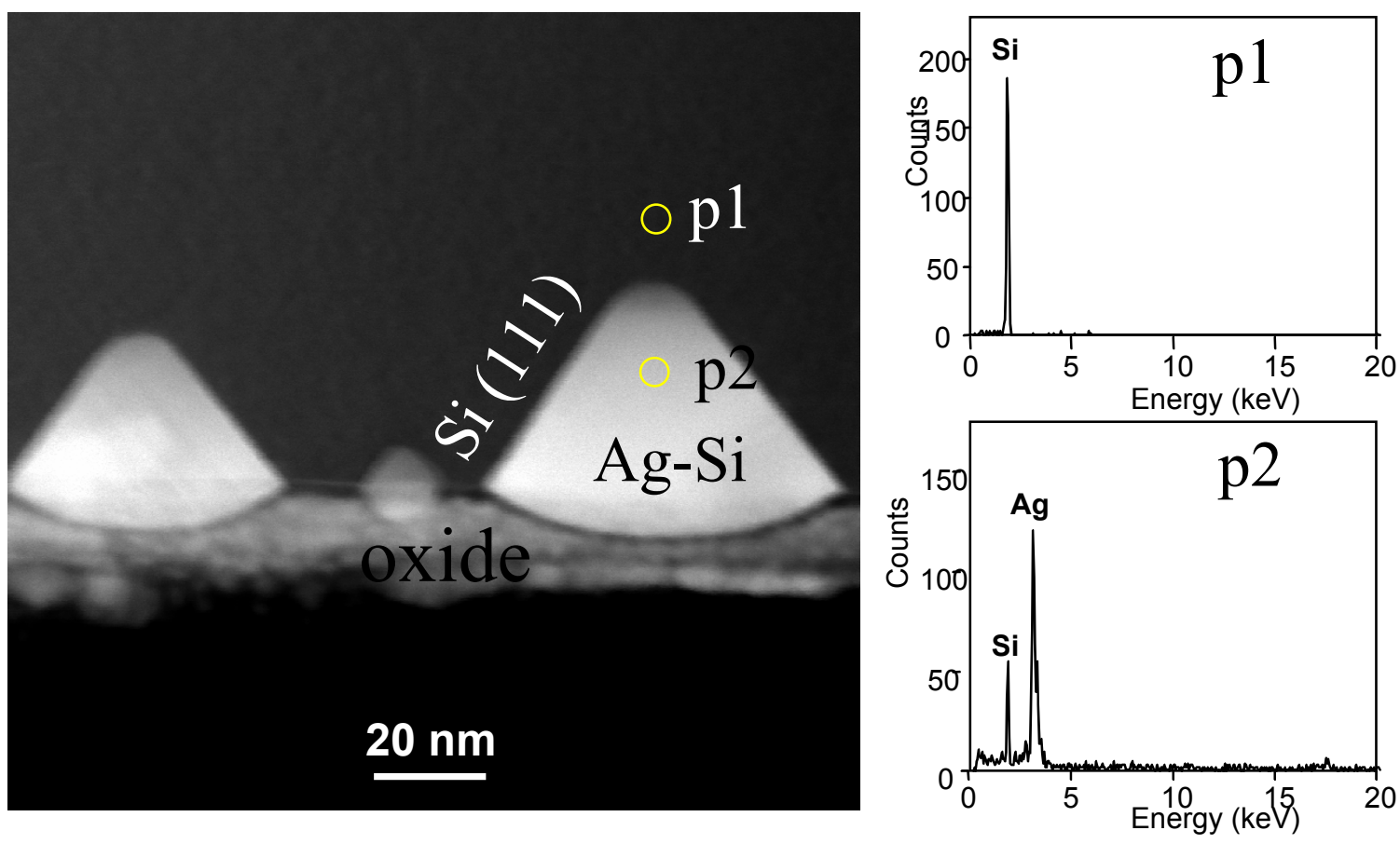

FIG 1. ADF-STEM image of Ag-Si precipitates in Si and corresponding EDS.

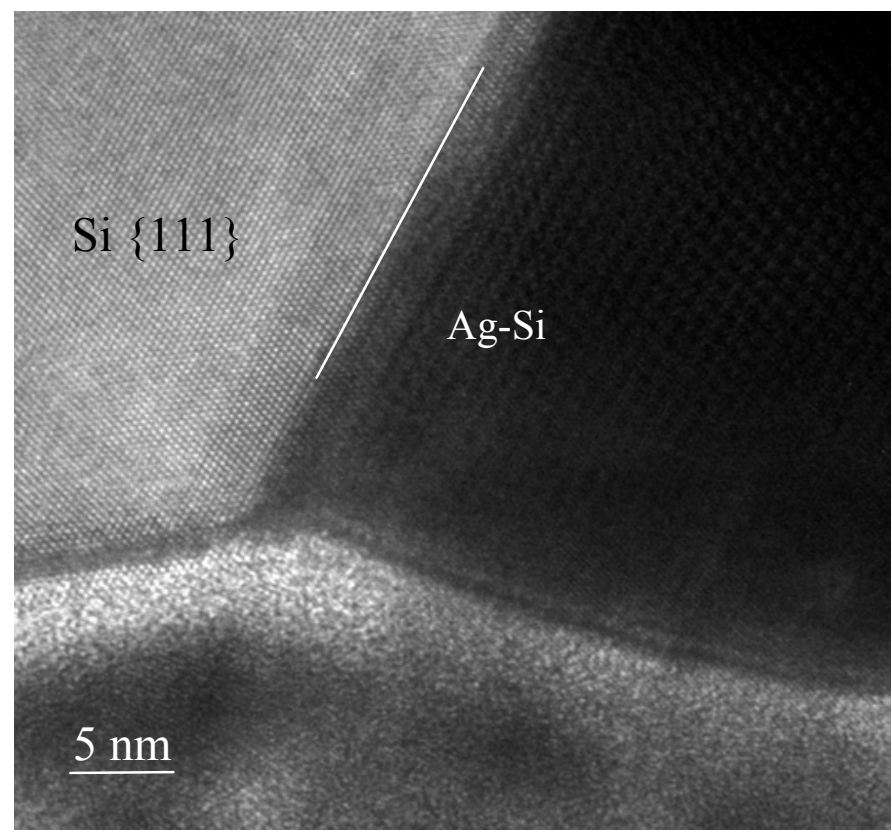

FIG. 2. High resolution lattice image of a Ag-Si precipitate showing the crystallographic relationship between $\mathrm{Ag}$ and $\mathrm{Si}$. 